\title{
A geopolítica do COVID-19
}

La géopolitique du COVID-19

The geopolitics of COVID-19

La geopolitica de COVID-19

Neli Ap. de Mello-Théry e Hervé Théry

\section{OpenEdition}

\section{Journals}

\section{Edição electrónica}

URL: http://journals.openedition.org/espacoeconomia/11224

DOI: 10.4000/espacoeconomia.11224

ISSN: 2317-7837

\section{Editora}

Núcleo de Pesquisa Espaço \& Economia

\section{Refêrencia eletrónica}

Neli Ap. de Mello-Théry e Hervé Théry, «A geopolítica do COVID-19 », Espaço e Economia [Online], $17 \mid$ 2020, posto online no dia 08 abril 2020, consultado o 21 abril 2020. URL : http://

journals.openedition.org/espacoeconomia/11224; DOI : https://doi.org/10.4000/espacoeconomia 11224

Este documento foi criado de forma automática no dia 21 abril 2020.

(C) NUPEE 


\title{
A geopolítica do COVID-19
}

\author{
La géopolitique du COVID-19
}

The geopolitics of COVID-19

La geopolítica de COVID-19

Neli Ap. de Mello-Théry e Hervé Théry

\section{Introdução}

1 A declaração do COVID-19 como pandemia, em 12 de março de 2020 pela Organização Mundial de Saúde (OMS) provocou efeitos em cadeia mundo afora. Enquanto alguns países se negaram às evidências e a seguir as sugestões, sobretudo de redução dos contatos sociais, outros decretaram confinamentos, mais ou menos rigorosos e mais ou menos tarde. A China, a Itália inicialmente e em seguida Espanha, França, Alemanha adotaram providencias semelhantes às sugeridas pela OMS. Fronteiras foram fechadas, viagens canceladas, deslocamentos proibidos. Viajantes passaram noites em aeroportos tentando voltar para seus países de origem. Governos anunciaram medidas sanitárias e econômicas visando reduzir, ao máximo, os reflexos negativos na economia e na saúde da população em geral. 0 mundo percebeu o quão frágil é o equilíbrio em que vivemos. 
Figura Comparação do fluxos aéreos mundiais em fevereiro e março de 2020

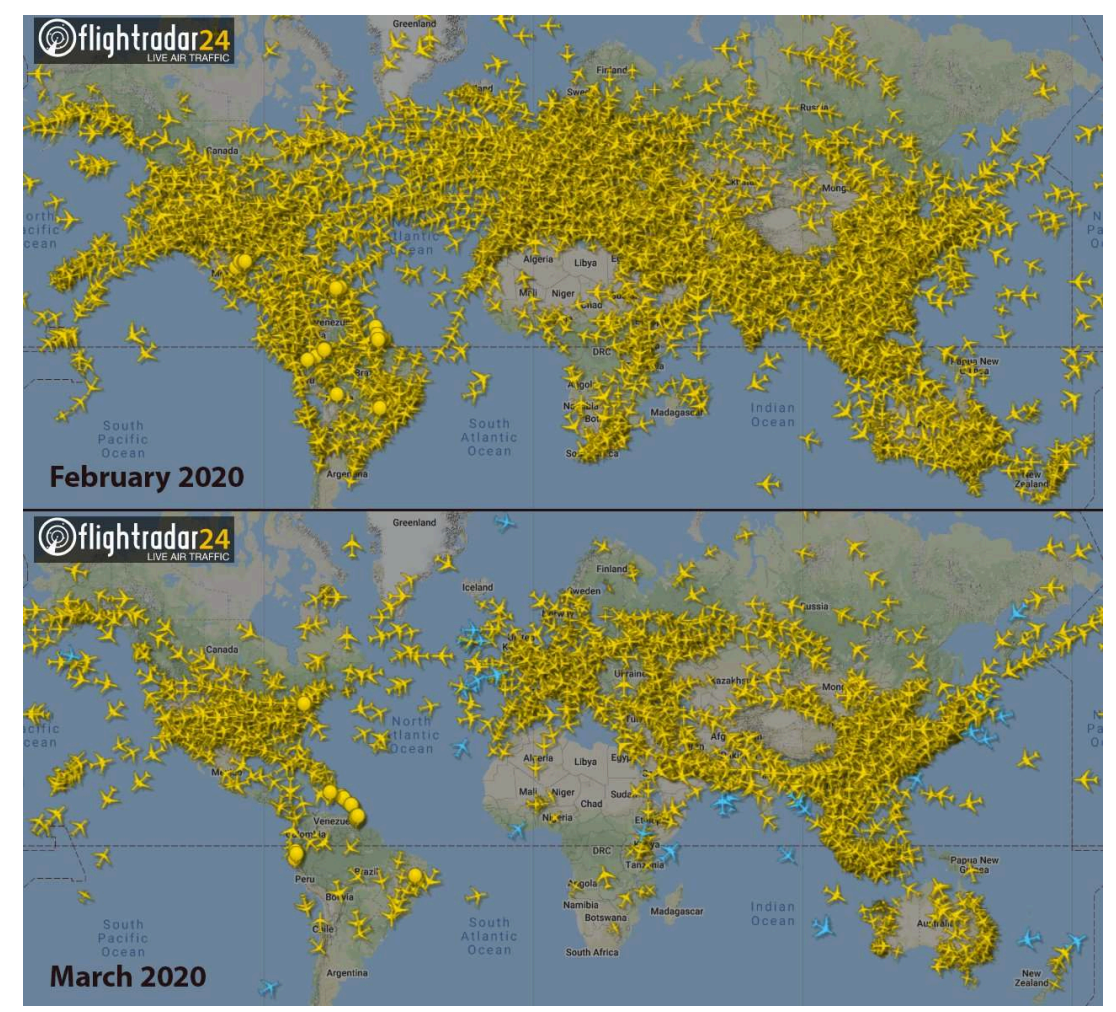

Fonte: FlightRadar24, publicado no Twitter

2 Como analisar geograficamente seus efeitos é o que nos propomos a apresentar neste artigo, estruturado em três partes. A primeira trata da interdependência do mundo atual em todos os segmentos da vida. Na segunda analisa-se a situação francesa e brasileira e as medidas governamentais tomadas e na terceira, o retorno para o local, da produção à comercialização.

\section{A interdependência que vivemos}

Desde há décadas sabemos que o mundo globalizado em algum momento se veria frente à uma grande crise. Já passamos por algumas no último século bem como no atual. Provavelmente tínhamos ideia de que seria uma crise no campo da economia e finanças, dada a predominância da financeirização global.

4 Não tínhamos ideia que poderia ser uma crise sanitária que nos colocaria frente a incertezas científicas, sociais, tecnológicas, econômicas e políticas, a riscos (inclusive olhando seus próximos como risco), perigos e, sobretudo, medos desconhecidos. Estamos diante do imprevisível assim como o número de pessoas contaminadas no mundo, que muda diariamente, tornando ainda mais difícil qualquer tentativa de cenarizar o futuro. 
Figura 2: População contaminada pelo vírus da Covid-19 (27.03.2020)

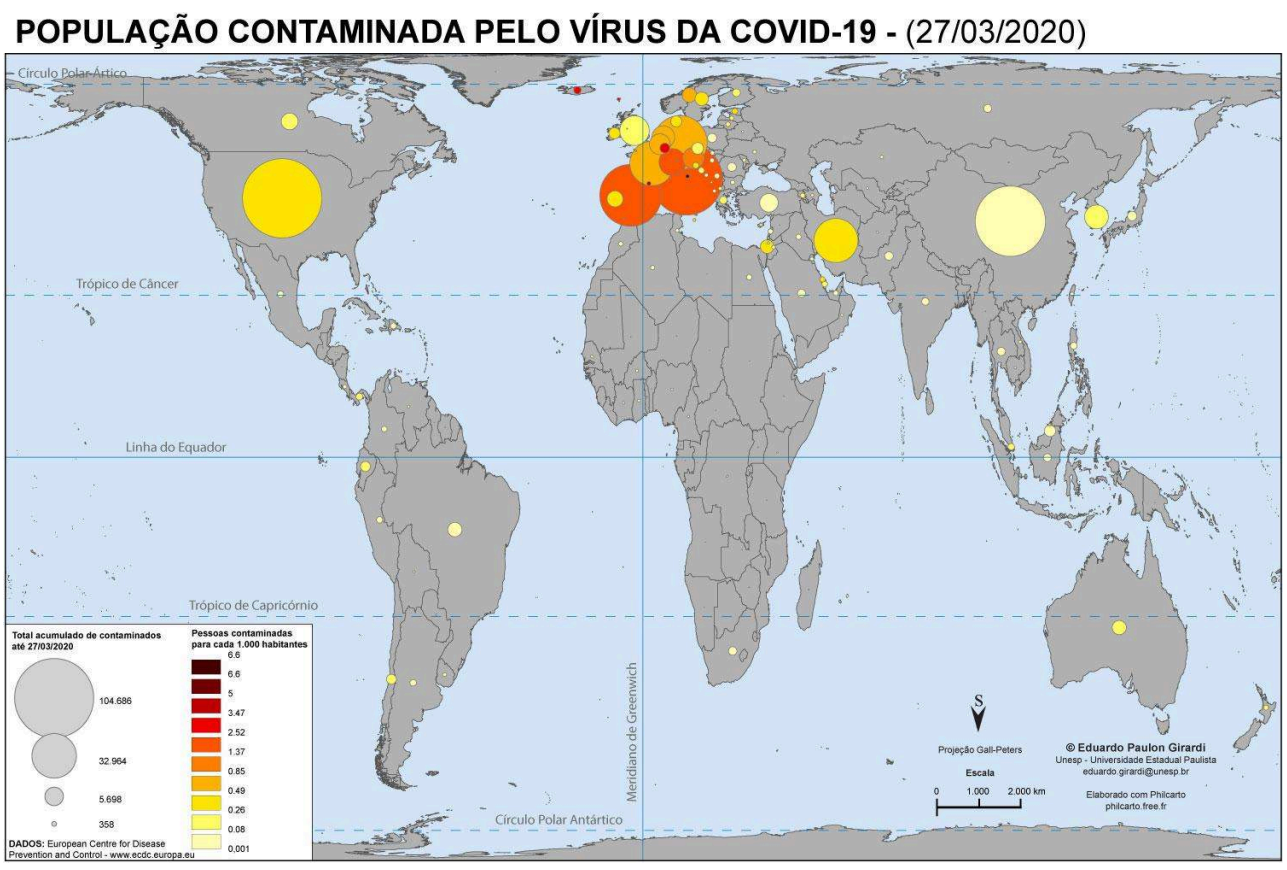

Fonte: Eduardo Paulon Girardi

5 No decorrer do século XX o planeta se transformou num mercado global, onde a interdependência é a característica principal. Qual é sua dimensão? Que segmentos elas atingem? Como lidar com elas e alterá-las?

6 A expansão do comércio mundial parecia ser infinita assim como as desterritorializações, principalmente da indústria. Países industriais visando diminuir seus custos, sobretudo com os direitos sociais, fecharam seus postos para abrí-los em outros países, especialmente na Ásia.

7 Sabíamos claramente da interdependência econômica, colocada em xeque pela crise de 2008 e da financeira: basta uma das bolsas ao redor do mundo perder valor, todas as outras despencam. A dependência alimentar também nos é conhecida, assim como o que se passa em alguns segmentos industriais e tecnológicos. 0 que não tínhamos ideia, porém, é da exata dimensão da interdependência na área da saúde e seus reflexos sobre as populações. Isto ficou visível nesta crise do Covid-19: no caso da União Europeia, ainda que os remédios sejam elaborados nos países integrantes, os princípios ativos são importados. Destes princípios dependem os medicamentos contra o câncer, os antibióticos e corticoides, as vacinas (DPT - difteria, tétano, coqueluche e BCG -bacillus Calmette Guérin e rubéola), os remédios para tratamento de pressão alta, das doenças cardíacas e do sistema nervoso. Basta uma das usinas fechar para que toda a cadeia, até chegar ao doente, seja interrompida e provoque danos.

Há 20 anos o mercado europeu dependia apenas de $20 \%$ de importações. Desde então as indústrias farmacêuticas europeias deslocaram a produção para a Ásia. Uma verdadeira divisão territorial do trabalho protagonizada pela China e Índia. Enquanto a primeira fornece os princípios ativos para o mundo todo, os produtos acabados são fabricados na Índia (embora se localize neste país a maioria dos locais de produção, a China lhe fornece $80 \%$ dos ingredientes farmacêuticos), ou seja, o laboratório do mundo é chinês. 
9 Na França, 8 entre 10 princípios ativos são importados dos 4442 locais de produção indianos e 2794 chineses (dados de julho de 2018), segundo a Agência Europeia de Medicamentos (EMA). Os países europeus importam também outros materiais essenciais para o segmento da saúde. Segundo a Agence Nationale de sécurité du médicament et des produits de santé https://www.ansm.sante.fr/Decisions/Injonctionsdecisions-de-police-sanitaire-sanctions-financieres-interdictions-de-publicite-

Injonctions a França tornou-se dependente de importações de produtos farmacêuticos em razão da decisão governamental de desenvolver os medicamentos genéricos visando, sobretudo, controlar os gastos públicos em saúde decorrentes também dos pagamentos para a Securité Sociale (Previdência pública). Por isso, à medida que o contágio pelo vírus avança, produtos de primeira necessidade - máscaras, respiradouros, leitos em hospitais entre outros - começaram a faltar.

Neste contexto, poderíamos falar em desglobalização como resultado dessa pandemia?

Economistas e sociólogos analisaram esse processo: em 2002 Philippin Walden Bello, economista, publicou "Deglobalization, Ideas for a New World Economy" livro onde ele parece ter sistematizado conceitos que ocorriam em vários ambientes e onde expressa modelos alternativos ao neoliberal, recomendando produzir para o mercado local ao invés de exportar e mostrando os perigos da interdependência entre as economias. Foi a ponta de lança para que muitos outros cientistas ampliassem as reflexões e análises desse processo, anteriormente minoritárias, procurando apontar caminhos que pareciam não ser possíveis. O sociólogo Alain Touraine publicou em 2007 "Penser autrement" no qual ele convida a pensar a concepção de sociedade em crise e a transformar a vida pessoal e coletiva.

12 Políticos e partidos políticos também se apropriaram do termo. Não ainda a sociedade. Talvez seja o momento de colocar na linha de frente os aprendizados dessa pandemia. Como podemos, nós geógrafos, contribuir na construção de novos paradigmas além do agir local e pensar global? Como aprender das experiências nacionais que essa pandemia nos impõe?

13 Alguns conceitos caros à Geografia como soberania, em suas diferentes acepções, se revalorizam.

\section{As conjunturas francesa e brasileira e as medidas tomadas}

14 As situações dos dois países são bem distintas. É nesse momento que o Estado tem que tomar as rédeas do processo e propor saídas tanto para empresas quanto para trabalhadores.

15 Embora criticada pela demora nas decisões, a presidência e o governo francês só decidem após discutirem as recomendações do Conselho científico, formado por médicos e cientistas (inclusive um sociólogo). O presidente francês, até esta data, fez três pronunciamentos, seguidos por falas do primeiro ministro para detalhamento das medidas. As determinações médicas e econômicas foram claras: reduzir o contato social para diminuir a superlotação dos hospitais e dar suporte financeiro para todos os segmentos econômicos, do pequeno empresário ao grande industrial, dos assalariados aos autônomos. Procurou limitar as perdas sociais e econômicas e reduzir o pânico. Tem sido bastante criticado porque faltam materiais de primeira necessidade aos 
serviços médicos e pela demora destes produtos chegarem aos diferentes setores locais onde há pessoas trabalhando, assim como pela demora no detalhamento de como serão implementadas as medidas econômicas. No momento, apenas $1 / 3$ da economia francesa está paralisado, outros $2 / 3$ continuam a produzir.

A solidariedade do setor privado com o segmento da saúde tem sido grande. Grupos econômicos, seja para reduzir a penúria de material, seja para manter suas indústrias e laboratórios funcionando, transformaram seus locais para produzir álcool gel, máscaras, luvas, respiradouros e os enviam gratuitamente para hospitais, casas de idosos, farmácias, empresas de alimentação e transportes. Até a indústria do luxo entrou no movimento, com a Dior, Givenchy e outros fazendo as suas linhas de fabricação de perfumes produzir gel hidroalcóolico. A produção, circulação e venda de produtos essenciais continua e tanto o presidente como o primeiro ministro prestaram homenagem aos trabalhadores da "segunda linha de defesa" contra o vírus (a primeira sendo os trabalhadores da saúde e a terceira os cidadãos que ficam em casa para não espalhar a doença). Dezenas de chefes de restaurantes famosos passaram a providenciar refeições para os trabalhadores da saúde (1500 delas no dia 29 de março) para manifestar concretamente a sua gratidão enquanto todos os restaurantes e bares estão fechados.

Em termos de distribuição espacial, no momento, predomina no leste e centro do país a maioria dos casos enquanto regiões no sul e sudoeste não os registram. A transferência (por helicóptero e por TGV - trens de grande velocidade) de doentes - do Leste para o oeste - para locais menos sobrecarregados é a medida mais recente para desafogar hospitais e reduzir a pressão sobre o corpo médico-hospitalar.

Figura 3 Situação da epidemia de Covid-19 na França dia 19 de março de 2020

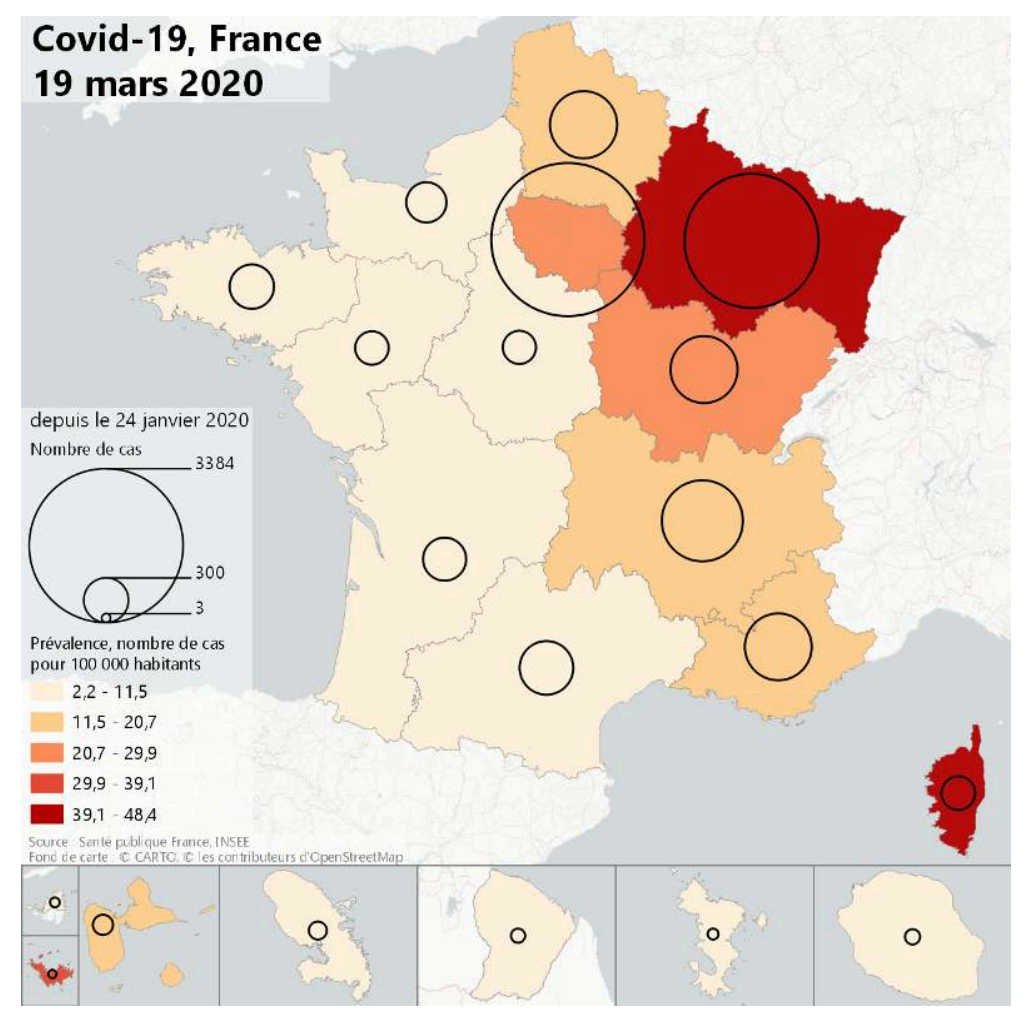

Fonte: Wikipedia, 210.147.125 
No caso brasileiro, sendo o país uma república federativa, Estados e Municípios têm autonomia e vêm tomando medidas restritivas semelhantes às de outros países. 0 governo federal tem protagonizado idas e vindas, enviando MP ao Congresso e as anulando no dia seguinte, critica governadores e prefeitos e continua, ainda, negando o problema tratando a pandemia como uma doença passageira. Tem insistido que todos setores econômicos continuem a produzir, propôs redução e corte de salário dos mais vulneráveis e, do valor orçamentário destinado a atender a crise, apenas $6 \%$ se destinam à população. Enquanto isso, o número de contaminados aumenta dia a dia $\mathrm{e}$ sobrecarrega o sistema de saúde.

Por outro lado, as universidades federais e estaduais investem em pesquisas específicas seja para vacinas, seja para identificar possíveis tratamentos assim como algumas empresas se disponibilizaram para contribuir com materiais necessários.

No entanto, na contramão das empresas francesas, os bancos situados no Brasil propuseram em 27 de março o aumento dos juros e o fim das negociações de dívidas.

\section{O uso dos produtos/comércio locais: uma decisão promissora na consolidação de novos paradigmas?}

21 No campo da soberania alimentar, muitas iniciativas de comércio local, de circuito curto experimentadas por associações e comunidades alternativas como nos conta Bénédicte Manier em seu livro "Un million de révolutions tranquilles" passam a ser vistas como possíveis caminhos. Experiencias em destinar a produção, até agora exportada, para os mercados locais são estimuladas, assim como a substituição nos supermercados de produtos importados por outros de origem local e podem significar a mudança de paradigmas e do modelo de globalização que vivemos.

Mundo afora o que era alternativo passa a ser visto como possibilidade, ganha novos contornos. Como exportar quando fronteiras estão fechadas? Produtos não perecíveis podem ser estocados por um tempo, ainda que os armazéns e depósitos não possuam capacidade infinita. Mas, e os perecíveis? Jogar fora quando há, no mundo todo, populações desprovidas? Doar ou vender localmente parecem ser as opções. São os modelos de desenvolvimento local que ganham força. Sachs $(1980,2004)$ já preconizava o desenvolvimento endógeno, includente, dependente de suas próprias forças e do fortalecimento do mercado interno. Momento para relembrá-lo e colocar em prática seus ensinamentos.

Na França aproxima o momento das colheitas e a falta de mão de obra, normalmente vinda dos outros países, assusta produtores. Voluntários locais se propõem a contribuir reforçando laços de solidariedade, substituindo o individualismo a que estamos acostumados. Empresas se reestruturam para produzir o que se tem necessidade no momento e fazem doação dos produtos. A maior cooperativa francesa de produção de açúcar (de beterraba) e álcool, Tereos, ofereceu gratuitamente a cada farmácia da região des Hauts de France, onde ela está localizada, 40 litros de álcool para poder produzir soluções hidroalcoólicas. E como ela têm usinas no Brasil, ela anunciou a doação de 20000 litros de álcool $70^{\circ}$ a hospitais e unidades regionais de saúde próximas as suas fábricas, na região noroeste do Estado de São Paulo.

Como será quando a pandemia passar? Seremos capazes de nos reinventar? 
No campo geopolítico, o mapa mundial se redesenha. A guerra comercial EUA-China deixa de ser notícia. Os EUA compram quase todo o estoque de máscaras produzidas na China. Ainda que seja em um plano estratégico, a pauta do momento é a solidariedade. China, Rússia e Cuba oferecem seus médicos e doam materiais para a Itália. EUA assumiu, inicialmente, o discurso negacionista, acompanhado pelo Brasil e México, embora tenha fechado as fronteiras para a Europa. À medida que o número de contaminados cresceu exponencialmente, modificou seu posicionamento.

Quando tudo passar, novas dissenções e novas relações de cooperação irão se estabelecer. Que países ganham e quais perdem?

\section{Conclusões}

Experiências tão massacrantes como a atual (e de outras semelhantes como a epidemia de Ebola na África, menos noticiadas), talvez somente os sobreviventes de guerra possam ter vivido. Não há dúvidas que haverão marcas profundas e, esperamos que uma nova sociedade, mais solidária seja um dos resultados.

Esse período serviu para mostrar a importância do Estado-providência, sustentando as perdas empresariais mas também as dos trabalhadores. Hora de repensar a política do Estado-mínimo.

o comércio internacional vai retomar o mesmo modelo ou criará novas formas? As desigualdades sociais poderão ser reduzidas? Regiões profundamente atingidas se reconstruirão em que bases? As cidades continuarão crescendo sem limites? As cidades menores serão capazes de demonstrar sua importância? Em 30 de março de 2020 não há, ainda respostas para muitas de nossas perguntas. As peças ainda se movem, rapidamente, no tabuleiro de xadrez mundial.

\section{BIBLIOGRAFIA}

https://www.ansm.sante.fr/Activites/Importation-et-Exportation/Importation-demedicaments/(offset)/ 1

https://www.lci.fr/sante/huit-substances-actives-de-medicament-sur-dix-fabriquees-hors-de-lue-comment-en-est-on-arrive-la-2129869.html

http://french.xinhuanet.com/2020-03/12/c_138868789.htm

Sachs, Ignacy. Stratégie de l'écodéveloppement. Paris. Eds. Ouvrières. 1980.

Sachs, Ignacy. Desenvolvimento includente, sustentável, sustentado. Rio de Janeiro. Ed. Garamond. 2004. 


\section{RESUMOS}

A crise sanitária de dimensões mundiais provocada pelo vírus COVID-19 tem resultado em situações semelhantes entre países de economia, cultura e políticas distintas. A acelerada dinâmica de contaminação e indícios que novos arranjos e estágios estão sendo esboçados apontam para possibilidade de mudanças no jogo geopolítico internacional. Um tabuleiro de xadrez onde as peças se movem cuidadosamente. Objetivando analisar seus efeitos socioterritoriais, o texto trata inicialmente da extrema interdependência que a globalização nos levou e dos questionamentos atuais a respeito de um processo inverso - desglobalizar, reterritorializar. Analisa, a seguir, as conjunturas francesa e brasileira e as diferentes medidas adotadas, o efeito territorial do vírus e o aparecimento de ações solidárias por parte de empresas. Um terceiro item explora se o retorno ao uso de produtos e comercio locais poderá significar possibilidades de aceitação e consolidação de novos paradigmas.

La crise sanitaire de dimensions mondiales provoquée par le virus COVID-19 crée des situations semblables dans des pays d'économie, de culture et politiques différentes. La dynamique accélérée de la contamination et de ses étapes déjà esquissées indiquent la possibilité de grands changements dans le jeu géopolitique international. Un échiquier où les pièces bougent avec précaution. Avec pour objectif d'analyser ses effets socio-territoriaux, le début de l'article montre l'interdépendance à laquelle la globalisation nous a amenée et les questions actuelles sur un processus inverse - déglobaliser, relocaliser. Il analyse ensuite les conjonctures française et brésilienne et les différentes mesures adoptées, les effets territoriaux du virus et l'apparition d'actions solidaires du côté des entreprises. Un troisième point analyse si le retour à l'usage de produits locaux pourrait signifier des possibilités d'acceptation et de consolidation de nouveaux paradigmes.

The global health crisis caused by the COVID-19 virus creates similar situations in countries with different economies, cultures and policies. The accelerated dynamics of contamination and its already outlined stages indicate the possibility of great changes in the international geopolitical game. A chessboard where the pieces move carefully. With the aim of analysing its socioterritorial effects, the beginning of the article shows the interdependence to which globalization has brought us and the current questions on a reverse process - deglobalizing, relocating. So it analyses the French and Brazilian conjunctures and the measures adopted, the territorial effects of the virus and the appearance of solidarity actions by companies. A third point underlines if the return to the use of local products could mean possibilities of acceptance and consolidation of new paradigms.

La crisis de salud global causada por el virus COVID-19 ha resultado en situaciones similares entre países con diferentes economías, culturas y políticas. La dinámica acelerada de la contaminación y las indicaciones de que se están esbozando nuevos arreglos y etapas apuntan a la posibilidad de cambios en el juego geopolítico internacional. Un tablero de ajedrez donde las piezas se mueven con cuidado. Con el objetivo de analizar sus efectos socioterritoriales, el texto aborda inicialmente la extrema interdependencia que nos ha traído la globalización y las preguntas actuales sobre un proceso inverso: desglobalizar, reterritorializar. A continuación, analiza las coyunturas francesas y brasileñas y las diferentes medidas adoptadas, el efecto territorial del virus y la aparición de acciones solidarias por parte de las empresas. Un tercer ítem explora si el retorno al uso de productos locales y comercio puede significar posibilidades de aceptación y consolidación de nuevos paradigmas. 
ÍNDICE

Palabras claves: Covid-19, geopolítica, Francia, Brasil, globalización.

Keywords: Covid-19, geopolitics, France, Brazil, globalization.

Palavras-chave: Covid-19, geopolítica, França, Brasil, globalização.

Mots-clés: Covid-19, géopolitique, France, Brésil, mondialisation.

\section{AUTORES}

\section{NELI AP. DE MELLO-THÉRY}

Professora titular na Escola de Artes, Ciências e Humanidades (EACH) da Universidade de São Paulo e coordenadora do grupo de pesquisa Políticas públicas, territorialidades e sociedade (IEA/ USP). Seus temas de pesquisa: Amazônia, gestão ambiental, dinâmicas territoriais, políticas ambientais e territoriais, desenvolvimento sustentável, gestão urbana e ordenamento territorial e políticas internacionais. É co-editora da Revista Confins (https://journals.openedition.org/ confins). Email: namello@usp.br

\section{HERVÉ THÉRY}

Pesquisador emérito do Centre National de la Recherche Scientifique (CNRS), professor de pósgraduação na Universidade de São Paulo (USP) e membro do Grupo de Pesquisa Políticas Públicas, Territorialidade e Sociedade (IEA/USP). Co-editor da revista Confins (https:// journals.openedition.org/confins). Áreas de pesquisa: Geografia, com ênfase em Geografia Regional, geografia do Brasil, geografia politica, cartografia tématica, modelização gráfica. Autor do Blog de recherche Braises (http://braises.hypotheses.org/). Email: hthery@aol.com 